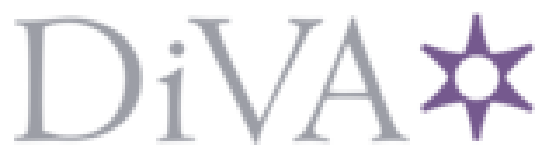

http://www.diva-portal.org

This is the published version of a paper presented at SEMC 2019.

Citation for the original published paper:

Tell, S., Andersson, A., Karoumi, R., Najafi, A., Spencer, Jr., B F. (2019)

Real-time hybrid simulation of a bridge-damper system

In: Alphose Zingoni (ed.), Advances in Engineering Materials, Structures and

Systems: Innovations, Mechanics and Applications: Proceedings of the 7th

International Conference on Structural Engineering, Mechanics and Computation

(SEMC 2019), September 2-4, 2019, Cape Town, South Africa (pp. 1810-1813). Cape

Town

N.B. When citing this work, cite the original published paper.

Permanent link to this version:

http://urn.kb.se/resolve?urn=urn:nbn:se:kth:diva-263159 


\title{
Real-time hybrid simulation of a bridge-damper system
}

\author{
S. Tell, A. Andersson, R. Karoumi \\ Royal Institute of Technology, Stockholm, Sweden
}

A. Najafi, B.F. Spencer Jr

University of Illinois at Urbana-Champaign, U.S.A.

\begin{abstract}
This paper presents the use of external dampers for vibration mitigation of railway bridges subjected to passing trains. A numerical model of the bridge combined with an experimental setup of a full-scale magnetorheological damper is used. The combined bridge-damper system is analyzed in real-time using a hybrid simulation technique. The approach is illustrated on a simply supported steel-concrete composite bridge. Due to the large eccentricity between the neutral axis and the roller support, the resulting displacement motivates the use of a near support damper. It is shown that sufficient vibration mitigation can be obtained with a single damper. A parametric study is performed to determine the optimal damper position and inclination.
\end{abstract}

\section{INTRODUCTION}

Railway bridges for high-speed lines need to fulfil certain criteria regarding the dynamic performance. Long and slender bridges may be prone to resonant loading from passing trains, resulting in excessive vibrations that can influence the riding comfort and track stability. At resonance, the vibration amplitude is inversely proportional to the damping and even a relatively moderate increase in structural damping of the bridge may result in a significant reduction of the dynamic response.

This paper presents a method of vibration mitigation using external dampers on railway bridges. The external dampers are mounted diagonally near the bridge support and make use of the eccentricity from the bridge bearing to the neutral axis of the bridge. A computationally efficient numerical model of the bridge-damper system has been developed, which is used in a Real-Time Hybrid Simulation (RTHS) test rig, comprising of a full-scale magnetorheological (MR) damper and a $200 \mathrm{kN}$ load actuator. The test rig is located at the Smart Structures Technology Laboratory at the University of Illinois at Urbana-Champaign. The response from passing trains is simulated with the numerical model and the displacement at the position of the damper is used as a real-time input for the load actuator that activates the MR-damper. Via a feedback control system, the response from the physical damper is sent back to the model.

\section{NUMERICAL MODEL}

The numerical model of the bridge is based on the work presented in Rådeström et al. (2017) and Tell, (2017). The model is illustrated in Figure 1. The work is based on an existing steel-concrete composite bridge and the following parameters are used; $L=42 \mathrm{~m}, E I=122 \mathrm{GNm}^{2}, m=18400 \mathrm{~kg} / \mathrm{m}, \zeta=0.5 \%$ and $e=2.2 \mathrm{~m}$. An external damper is mounted at a distance $x_{\mathrm{d}}$ and angle $\alpha$ from the roller support.

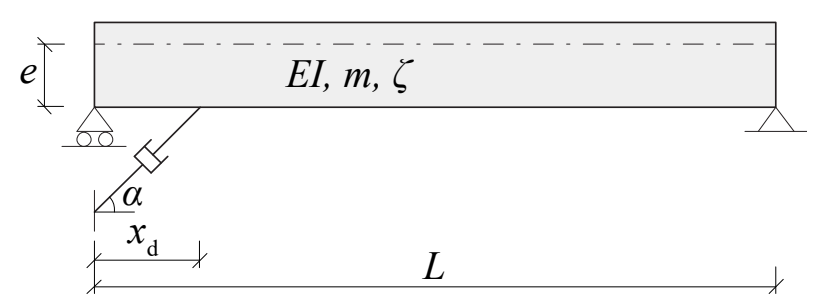

Figure 1. Illustration of the bridge-damper system.

The performance of the system depends on the displacement along the line of action of the damper. Due to the relatively large eccentricity, the displacement at the roller support is significantly larger than at the fixed support, illustrated in Figure 2. The model is described in modal domain where the mode shape is a 
combination of the vertical and longitudinal translation. Omitting the longitudinal component would generally underestimate the performance.
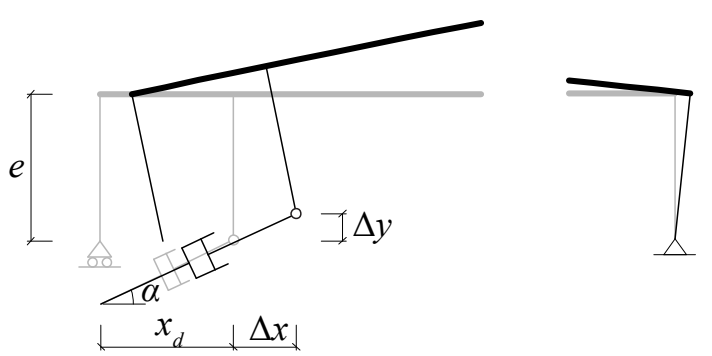

Figure 2. Schematic of the damper displacement.

The first four mode shapes of the bridge deck is presented in Figure 3. The first mode is in good agreement with a simple sine function, but higher modes are influenced by the eccentricity. This has been solved numerically assuming Euler-Bernoulli beam theory. The modal values for the point connecting the damper to the bridge deck is presented in Table 1. It shows that the horizontal component is significant for all studied modes. The modal mass and natural frequencies are given in Table 2.

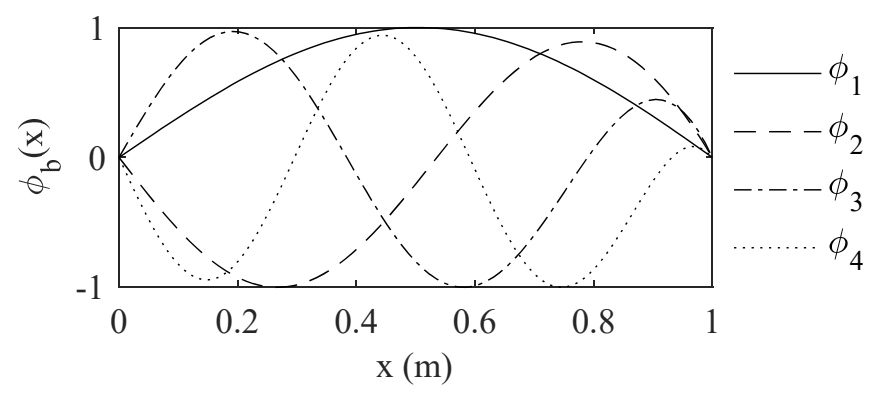

Figure 3. Vertical mode shapes of the bridge deck.

Table 1: Modal values for the damper, $x_{\mathrm{d}}=2.0 \mathrm{~m}$.

\begin{tabular}{lcccc}
\hline & mode 1 & mode 2 & mode 3 & mode 4 \\
\hline$\phi_{\text {d,hor }}$ & 0.332 & 0.104 & 0.913 & -0.160 \\
$\phi_{\text {d,vert }}$ & 0.148 & -0.277 & 0.368 & -0.457 \\
\hline
\end{tabular}

Table 2: Modal masses and natural frequencies.

\begin{tabular}{ccccc}
\hline & mode 1 & mode 2 & mode 3 & mode 4 \\
\hline$M($ ton $)$ & 388 & 352 & 311 & 327 \\
$f(\mathrm{~Hz})$ & 2.23 & 8.11 & 15.51 & 26.18 \\
\hline
\end{tabular}

The high-speed train load model in EN 1991-2 is adopted. HSLM-A4 is found to be the most critical train, with a coach length of $21 \mathrm{~m}$ and axle load of $190 \mathrm{kN}$. Given the natural frequencies in Table 2 the critical train speed is about $170 \mathrm{~km} / \mathrm{h}$, well within realistic operating speeds for many railway lines.

\section{HYBRID SIMULATION SETUP}

The procedure for the hybrid simulation has been developed in MathWorks Simulink. The equation of motion of the bridge model is described in state-space form using the system matrices $\mathbf{A}$ and $\mathbf{B}$ together with the output matrix $\mathbf{C}$ and feedthrough matrix $\mathbf{D}$ according to Equation (1). The modal vectors for the bridge is denoted $\phi_{\mathrm{b}}$ and the modal coordinates at the bridgedamper location is denoted $\phi_{\text {d. }}$. The input consists of a modal load vector $F_{\text {train }}$ for each mode and the output is the displacement, velocity and acceleration of the bridge deck as well as the displacement at the position of the damper.

$$
\begin{aligned}
& \mathbf{A}=\left[\begin{array}{cc}
0 & \mathbf{I} \\
-\mathbf{M}^{-1} \mathbf{K} & -\mathbf{M}^{-1} \mathbf{C}
\end{array}\right], \mathbf{B}=\left[\begin{array}{cc}
0 & 0 \\
\mathbf{M}^{-1} & -\boldsymbol{\phi}_{\mathrm{d}} \mathbf{M}^{-1}
\end{array}\right] \\
& \mathbf{C}=\left[\begin{array}{cc}
\boldsymbol{\phi}_{\mathrm{d}} & 0 \\
\boldsymbol{\phi}_{\mathrm{b}} & 0 \\
0 & \boldsymbol{\phi}_{\mathrm{b}} \\
-\mathbf{M}^{-1} \mathbf{K} & -\mathbf{M}^{-1} \mathbf{C}
\end{array}\right], \mathbf{D}=\left[\begin{array}{cc}
0 & 0 \\
\mathbf{M}^{-1} & -\boldsymbol{\phi}_{\mathrm{d}} \mathbf{M}^{-1}
\end{array}\right]
\end{aligned}
$$

The layout for the hybrid simulation setup is illustrated in Figure 4. For each time increment the displacement $d_{\text {damper }}$ along the line of action of the damper is calculated and sent as a controlled input displacement to the experimental load actuator. The resulting restoring force due to the MR-damper is sent back as an input force $F_{\text {damper }}$ to the model. To avoid instability of the real-time experimental setup, a feedforward control is used. Both the control and the data acquisition system is managed via ControlDesk from dSPACE. A photo of the full-scale MR-damper is shown in Figure 5. The RTHS system is further described in Phillips \& Spencer (2011) and (2012). It was also demonstrated on a 3-story building in Phillips \& Spencer (2013).

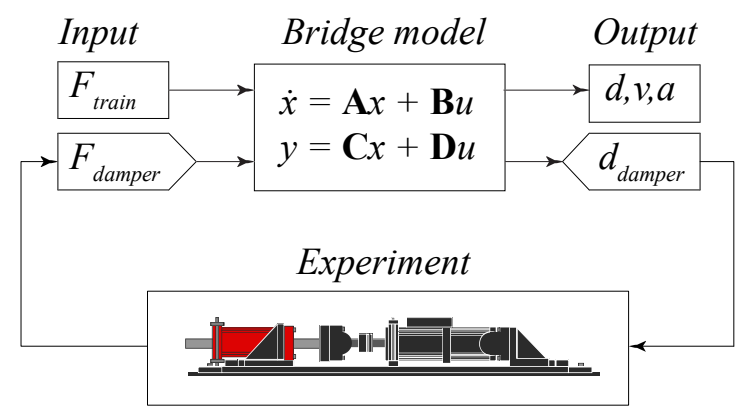

Figure 4. Layout for the hybrid simulation setup.

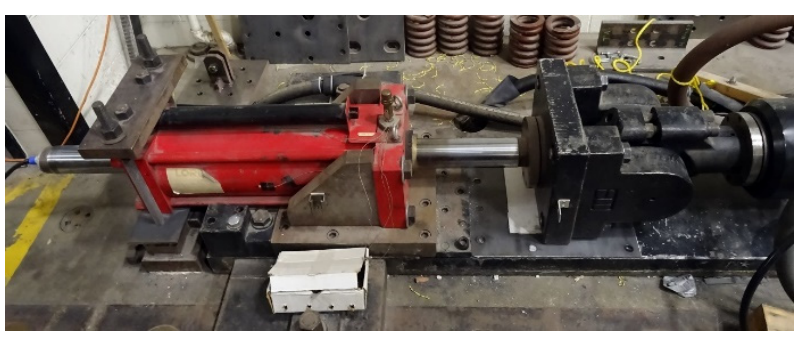

Figure 5. Photo of the MR-damper in the experimental setup. 


\section{RESULTS}

The properties of the MR-damper were characterized under different harmonic loadings, excluding the bridge model. Vital parts of the MR-damper are small steel particles suspended in the damper fluid and a large steel coil around the housing. By applying an electric current to the steel coil, the electromagnetic field will polarize the particles that will change the rheological properties of the fluid and hence alter the response of the damper. A small-scale model of a similar damper was studied by Spencer et al. (1997).

An example of the restoring force under different electric currents is shown in Figure 6. The input consists of a $2 \mathrm{~Hz}$ harmonic displacement with $5 \mathrm{~mm}$ amplitude. The restoring force is relatively small when no current is applied but reach about $100 \mathrm{kN}$ for $2 \mathrm{amp}$ current. Due to the visco-plastic characteristics of the fluid at high electric currents, a near rectangular load-displacement hysteresis is obtained.
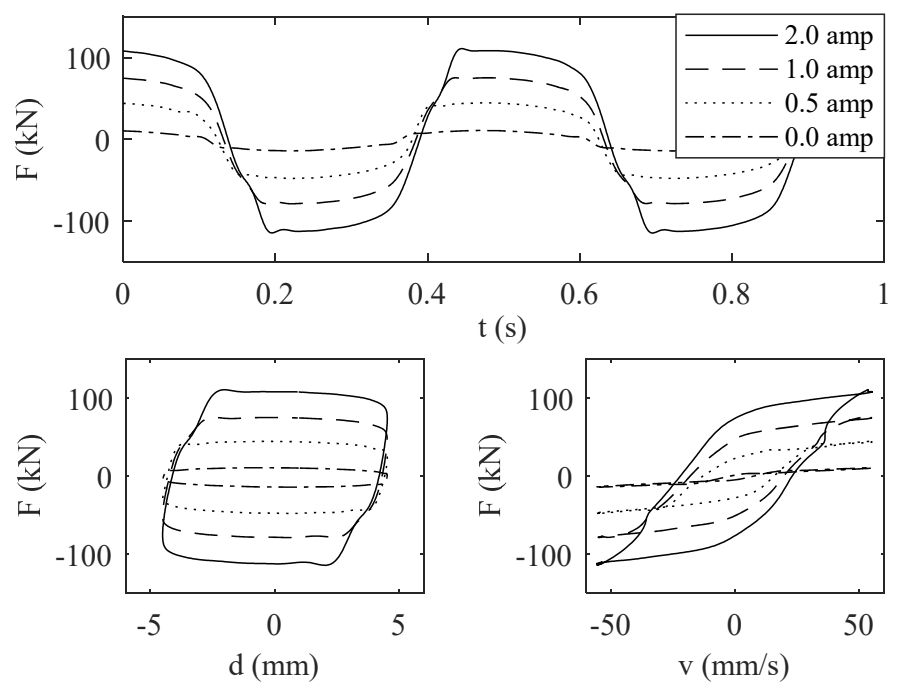

Figure 6. Time response from the MR-damper when subjected to a harmonic input displacement at different currents.

In the RTHS, the train load HSLM-4 is simulated at different speeds. The peak deck acceleration for each speed is presented in Figure 7 for different currents of the MR-damper. In all cases $x_{\mathrm{d}}=2.0 \mathrm{~m}$ and $\alpha=0^{\circ}$. The current is held constant during each train passage. The design criteria according to Eurocode EN 1990 is a peak vertical deck acceleration of $3.5 \mathrm{~m} / \mathrm{s}^{2}$ for bridges with ballasted tracks. Using a single MR-damper, a current of at least $1 \mathrm{amp}$ is required. The resulting displacement of the damper is about $5-15 \mathrm{~mm}$ according to Figure 8 . The time response for the bridge deck acceleration at resonance is shown in Figure 9, the amplitude is reduced by a factor 2 when the current is increased from 0 to $2 \mathrm{amp}$.

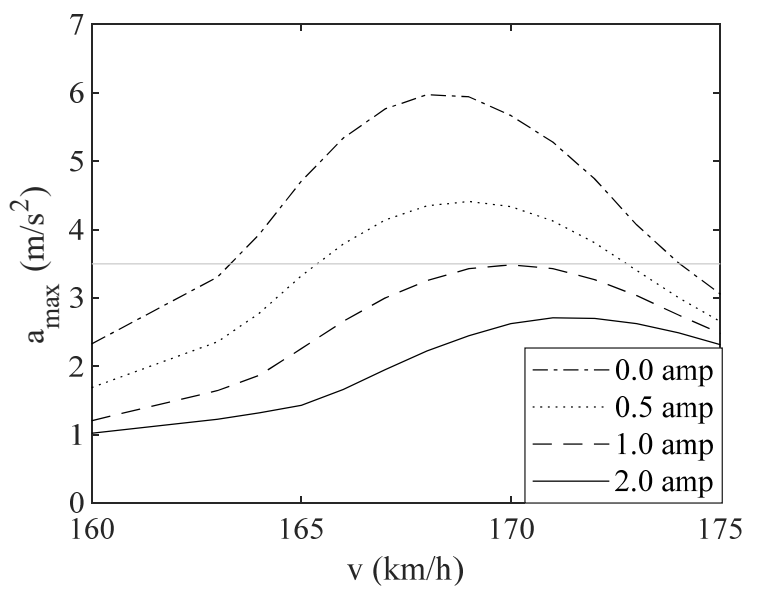

Figure 7. Envelope of peak acceleration for HSLM-A4.

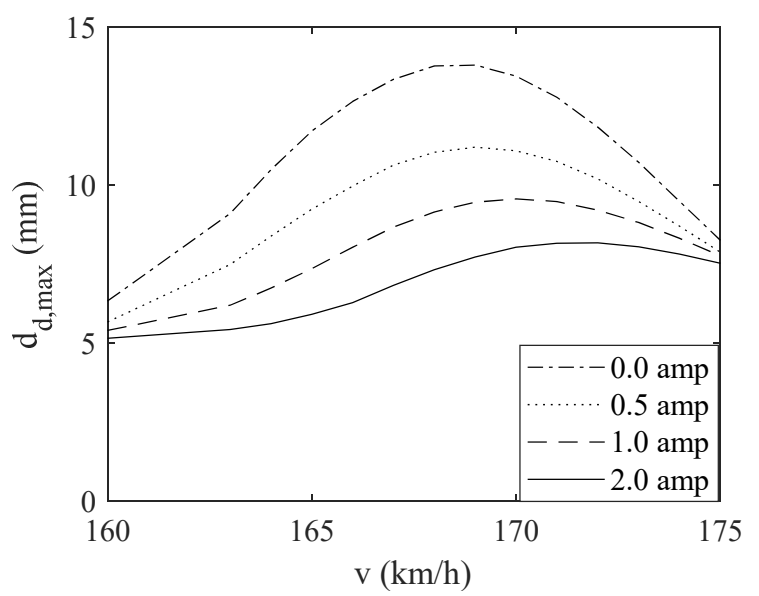

Figure 8. Envelope of peak damper displacement for HSLM-A4.

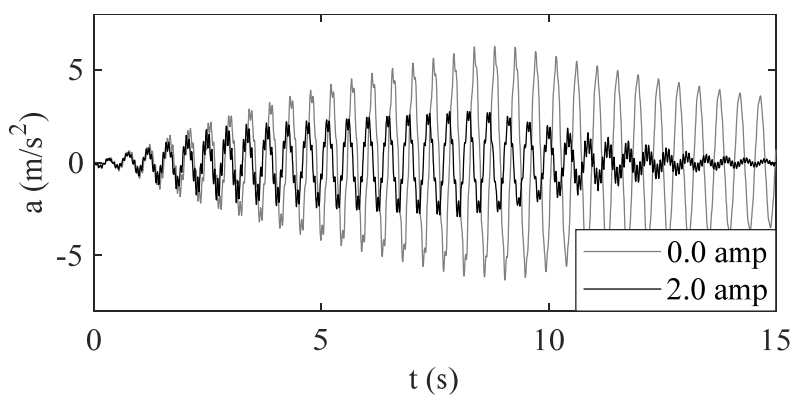

Figure 9. Time response for the case with 0 and 2 amp, HSLMA4 at resonance speed.

A parametric study is undertaken to determine the optimal damper position and inclination. The objective is to minimize the vertical deck acceleration.

Figure 10 shows the results for a single damper at the roller support, for the case of 2 amp current. When mounted near the support a horizontal damper is most efficient. When extending the connection point $x_{\mathrm{d}}$ the optimal angle increases to $45^{\circ}$.

If instead installing the damper at the fixed support, results according to Figure 11 is obtained. The optimal solution is then a vertical damper, which in many cases would be impractical and obstruct the way under the bridge. 


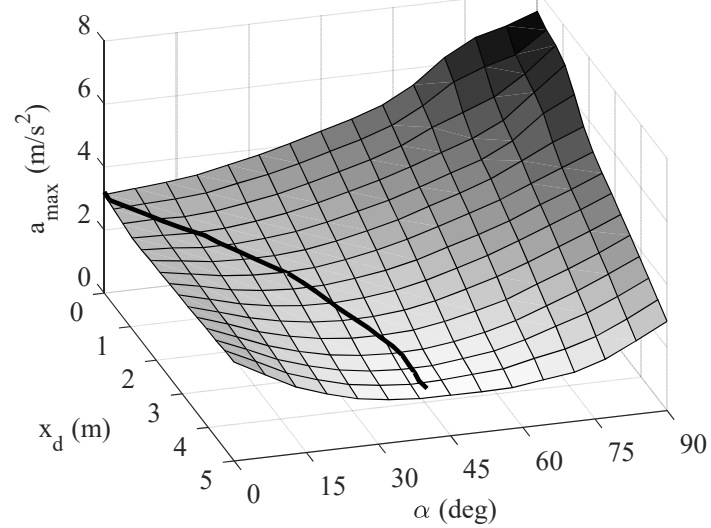

Figure 10. Peak deck acceleration for different damper positions near the roller support, $2.0 \mathrm{amp}$ current.

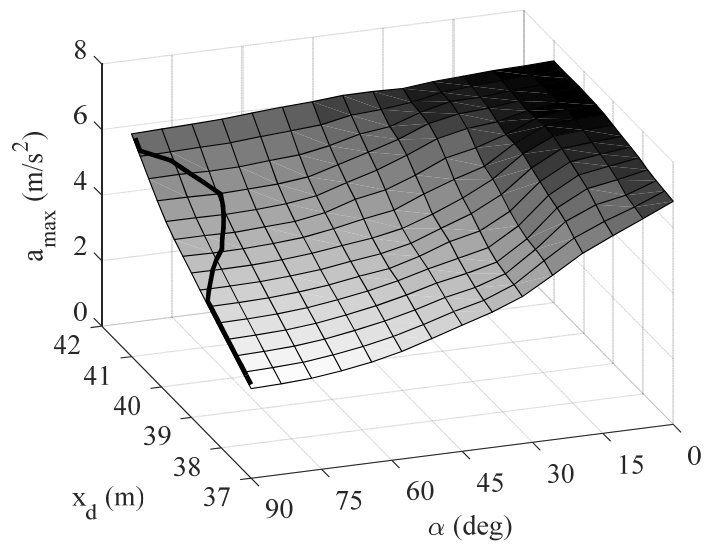

Figure 11. Peak deck acceleration for different damper positions near the fixed support, 2.0 amp current.

\section{CONCLUSIONS}

This paper has illustrated the use of a real-time hybrid simulation for a bridge-damper system. The main advantage is that the in-situ properties of the real damper is accounted for. The approach is very versatile and can be used to describe arbitrary structures. The RTHS framework was able to produce reliable results under various loading conditions.

For the studied bridge it was found that the damper performs best when mounted at the roller support. This is due to the longitudinal component of the bridge displacement owing to the eccentricity. If mounted near the roller support, a horizontal position of the damper shows the best performance. If mounted further away from the support the optimal angle will reach $45^{\circ}$. It is less efficient to install the damper at the fixed support and would in that case require a near vertical damper.

\section{ACKNOWLEDGEMENTS}

The work with the real-time hybrid simulations was performed at the Smart Structures Technology Laboratory at the University of Illinois at Urbana-Champaign and partly funded by the EU-project RISEN (H2020-MSCA-RISE-RISEN).

\section{REFERENCES}

Rådeström, S., Ülker Kaustell, M., Andersson, A., Tell, V., Karoumi, R., 2017. Application of fluid viscous dampers to mitigate vibrations of high-speed railway bridges. International Journal of Rail Transportation 5 (1), 47-62.

Tell, S., 2017. Vibration mitigation of high-speed railway bridges: Application of fluid viscous dampers. Licentiate thesis, Division of Structural Engineering and Bridges, KTH.

Phillips, B.A., Spencer, B.F., 2011. Model-Based FeedforwardFeedback Tracking Control for Real-Time Hybrid Simulation. Report NSEL-028, UIUC.

Phillips, B.A., Spencer, B.F., 2012. Model-Based Framework for Real-Time Dynamic Structural Performance Evaluation. Report NSEL-031, UIUC.

Phillips, B.A., Spencer, B.F., 2013. Model-Based Multiactuator Control for Real-Time Hybrid Simulation. Journal of Engineering Mechanics 139(2), 219-228.

Spencer, B.F., Dyke, S.J., Sain, M.K., Carlson, J.D., 1997. Phenomenological model for magnetorheological dampers. Journal of Engineering Mechanics 123(3), 230-238. 